\title{
NUEVAS PERSPECTIVAS EN EL DEBATE SOBRE LA NATURALEZA HUMANA
}

ALFREDO MARCOS

Universidad de Valladolid.

\begin{abstract}
RESUMEN: En un artículo anterior, titulado Filosofía de la naturaleza humana, he expuesto mi posición crítica respecto de las corrientes que abogan por la negación de la naturaleza humana, por su completa naturalización o por su completa artificialización. Aquí haré un breve resumen de esta posición (apartado 1), para a continuación profundizar en las críticas, pero ya en diálogo con varios autores que configuran un cambio de perspectiva contemporáneo respecto de la cuestión (apartado 2). En su conjunto, estos autores presentan una crítica muy lúcida al naturalismo vigente, así como sugerencias interesantes para una nueva y más acertada teoría de la naturaleza humana. Me detendré especialmente en las aportaciones de Thomas Nagel, porque creo que echan las bases para un posible diálogo constructivo, en torno a la naturaleza humana, entre posiciones teístas y no teístas (apartado 3). Este diálogo ha de apoyarse, según defiendo en el apartado conclusivo, en las indicaciones del sentido común crítico (apartado 4)., anidación, fecundación, diálogo.
\end{abstract}

PALABRAS CLAVE: naturalismo radical, materialismo, naturalismo moderado, antropotecnia, sentido común.

\section{New perspectives in the debate about human nature}

ABSTRACT: In a previous article, entitled Philosophy of Human Nature, I have stated my criticism against the denial of human nature, against their complete naturalization and against its complete artificialization. Here I will give a brief summary of these arguments (section 1). Then I will try to deepen the criticism in dialogue with several contemporary authors who shape a crucial change in the current perspectives on human nature (section 2). Taken together, these authors present a lucid review of the radical naturalism. They suggest as well a new and more accurate theory of human nature. I will focus especially on the contributions of Thomas Nagel, because I believe that he lays the foundation for a possible constructive interchange on human nature between theistic and non-theistic positions (section 3). This dialogue should be oriented, as I argue in the concluding section, by the guidelines of a critical common sense.

KEY WORDS: radical naturalism, materialism, moderate naturalism, anthropotechnics, common sense.

\section{NEGACIÓN, NATURALIZACIÓN Y ARTIFICIALIZACIÓN DE LA NATURALEZA HUMANA}

Entre las teorías de la naturaleza humana ${ }^{1}$, destaca la idea de que el ser humano simplemente carece de naturaleza propia, que es pura libertad, que se determina a sí mismo y se autoconstruye poco menos que a voluntad y desde la voluntad. Se suele citar como precedente en esta línea un texto del pensador renacentista Pico della Mirandola. En el mismo, Dios le habla a Adán con estas palabras: "No te he dado ni un lugar determinado, ni un aspecto propio, ni una prerrogativa peculiar con el fin de que poseas el lugar, el aspecto y la prerrogativa que conscientemente elijas y que de acuerdo con tu intención obtengas y conserves. La naturaleza definida de otros seres está constreñida

\footnotetext{
1 Cf. Marcos, A. (2010): «Filosofía de la naturaleza humana», Eikasia. Revista de Filosofía, año VI, 35, pp. 181-208.
} 
por las leyes por mí prescritas. Tú, en cambio, no constreñido por estrechez alguna te la determinarás según el arbitrio a cuyo poder te he consignado»².

Se trata, sin duda, de una ingenua exageración, propia de un humanismo recién estrenado. El ser humano posee libertad y arbitrio, pero no está exento de condicionamientos de diverso tipo, entre los que cuentan aquellos que derivan de su propia naturaleza. Sin embargo, otros autores posteriores, desde las más diversas corrientes filosóficas, ilustración, idealismo, marxismo, conductismo, historicismo y, muy especialmente, desde el existencialismo y el nihilismo, han insistido sobre esta idea del ser humano como ajeno a cualquier naturaleza dada. Hoy día, esta perspectiva está presente en el post-humanismo de raíz nietzscheana defendido por autores como el alemán Peter Sloterdijk ${ }^{3}$.

Sin naturaleza humana no habría nada en común entre el ser humano y la propia naturaleza, ni entre los humanos mismos, apresado cada cual en su incondicionada libertad y en su voluntad de poder. Este "hombre sin lugar, aspecto ni prerrogativa» tendría que dedicar toda su vida a decidir qué ha de hacer con la misma, desde cero, en un vacío de valores.

No dedicaré más tiempo a la crítica de esta posición extravagante, que solo por efecto las modas intelectuales recurrentes puede tener algún atractivo. Apliquemos aquí la simple sensatez basada en nuestra experiencia cotidiana: somos libres, sí, pero no de modo total e incondicionado. Y si careciésemos por completo de condicionamientos, ni siquiera podríamos ejercer nuestra libertad. Kant lo dijo en atinada metáfora: la paloma que nota la resistencia del aíre piensa que volaría mejor sin él, pero el caso es que sin esa resistencia, que condiciona y limita el vuelo, ni siquiera podría volar ${ }^{4}$.

En el otro extremo - más bien en el otro exceso- encontramos las posiciones naturalistas radicales. Según estas, el ser humano es eso, naturaleza y solo naturaleza. La pregunta por el hombre tendría, así, una sencilla respuesta: cada uno de nosotros es un organismo de la especie Homo sapiens, un primate ${ }^{5}$.

Curiosamente, las posiciones que en principio parecen contrarias producen los mismos efectos. La convergencia de la naturalización y de la negación se aprecia ya en Nietzsche, uno de los autores que más influyen tanto en los negadores de la naturaleza humana, como en los partidarios de su plena naturalización. Esta conexión produce también una agenda similar: trans-humanista, al estilo oxoniense, o post-humanista, al estilo continental ${ }^{6}$. Desde ambas partes — negadores y naturalizadores de la naturaleza humana- se propone una profunda modificación y artificialización del ser humano,

2 Pico della Mirandola (2004): Discurso sobre la dignidad del hombre. México: UNAM, p. 14 (traducción de A. Ruiz Díaz).

3 La negación de la naturaleza humana también está presente, de un modo u otro, en algunas formas ideológicas o culturales contemporáneas, como por ejemplo en la ideología de género o en ciertas prácticas, pretendidamente artísticas, de modificación del cuerpo humano. No entro aquí en este terreno, sino que me limito a dialogar con algunas formas filosóficas de la negación de la naturaleza humana.

4 Cf. Kant, I. (1978): Crítica de la Razón Pura. Madrid: Alfaguara, pp. $46-47$ (traducción de P. Ribas, Kvr, Introducción, B9).

5 Una clara exposición de esta teoría puede verse en Mosterín, J. (2006): La naturaleza humana. Barcelona: Espasa.

6 Nick Bostrom niega que la influencia de Nietzsche sobre el transhumanismo haya sido tan decisiva. Sin embargo, otros autores, como Stefan L. Sorgner han mostrado que hay en Nietzsche base textual suficiente como para afirmar una fuerte afinidad entre su filosofía y el transhumanismo contemporáneo. Cf. Bоsтrom, N. (2005): "A history of transhumanist thought». Journal of Evolution and Technology. 14/1; Sorgner, S. L. (2009): «Nietzsche, the Overhuman, and Transhumanism». Journal of Evolution and Technology. 20/1. 
«mejora» (enhancement), lo llaman. En última instancia, si la naturaleza humana es plenamente natural, entonces es técnicamente disponible, y si la naturaleza humana simplemente no existe, entonces tenemos la tarea de inventarla técnicamente. La antropotecnia, está indicada en ambos casos ${ }^{7}$.

El naturalismo al uso se edifica sobre el solar del viejo materialismo, cuyas bases fueron fallando a medida que se desarrollaba la física contemporánea. Hay autores, incluso, que consideran ambos términos simplemente como sinónimos. Según Francisco Soler: «El "naturalismo" está de moda en el pensamiento contemporáneo. Y hay quienes se esfuerzan por marcar las distancias entre "naturalismo" y "materialismo", con el argumento de que el naturalista no sostiene que todas las realidades son materiales, sino tan sólo que todo lo que existe es parte de la naturaleza, y puede ser estudiado científicamente. Pero como en cualquier caso se da por supuesto que la base de la naturaleza (de la que todo lo existente depende) es material, el naturalismo viene a ser, a la postre, una variante más del materialismo» ${ }^{8}$.

No obstante, por razones que irán apareciendo más abajo, especialmente en el diálogo con Thomas Nagel, habría que distinguir entre un naturalismo moderado y uno radical. Según el primero, que suscribo sin reservas, y que es compatible con posiciones teístas, las ciencias naturales son importantes para comprender al ser humano9. Para el segundo, todo lo humano es reductible a su base física y biológica. A este último va dirigida mi crítica y a este me referiré mientras no señale lo contrario.

En todo caso, se puede entender perfectamente que algunos prefieran cambiar la terminología y presentarse como naturalistas en vez de como materialistas. La irrupción en física de las ideas de campo y de onda, la conexión entre materia y energía descubierta por Einstein, la indeterminación cuántica formulada por Heisenberg, el descubrimiento de la estructura del átomo, compuesto por una pléyade de entidades en sucesivos niveles subatómicos y la cosmología del Big Bang, han minado los cimientos del viejo materialismo. De hecho, nadie se atrevería hoy día a ofrecer una caracterización positiva y precisa de lo que vendría a ser la materia última del universo. Con ello, el materialismo, o naturalismo radical, ha llegado a convertirse en una tesis puramente teológica, cuyo contenido se reduce a la mera negación de la realidad de Dios.

Los materialistas históricos soñaban con un mundo completamente explicable en términos de partículas corpusculares simples que se mueven eternamente de modo determinista en el espacio vacío. Pero las partículas resultaron ser muy complejas en el fondo, mezcla de corpúsculo y onda, con momento y movimiento indeterminados, el espacio resultó mucho más retorcido de lo esperado y el tiempo, finito de cabo a rabo. Añadamos a esto el impresionante desarrollo actual de la biología, que ha hecho simplemente inviable cualquier intento de reducción masiva de esta ciencia a la física. En consecuencia, el materialismo del momento, bajo la denominación de naturalismo, se ha visto obligado a buscar apoyo más «arriba», en la propia biología. En especial dos territorios de investigación están siendo explotados como base legitimadora por el vigente naturalismo: el darwinismo en sus múltiples variantes y las neurociencias.

En sintonía con estas apreciaciones podemos leer el siguiente texto de la filósofa británica Mary Midgley: «Este libro — dice en Science and Poetry — trata sobre la identidad

7 Cf. Marcos, A. (2010): «Filosofía de la naturaleza humana». Eikasia. Revista de Filosofía. VI, 35. http://www.revistadefilosofia.com

8 Soler, F. (2013): Mitología materialista de la ciencia. Madrid: Encuentro, p. 20.

9 Por ejemplo, la importancia de las neurociencias para comprender la racionalidad humana se aprecia perfectamente en ConILl, J. (2013): «Neurorracionalidad práctica y valor biológico», Daimon. Revista Internacional de Filosofía, n ${ }^{\circ}$ 9, pp. 89-102. 
personal, sobre quiénes y qué somos. Trata sobre la unidad de nuestras vidas. Intenta sugerir cómo podemos resistir las modas académicas que actualmente nos fragmentan». Midgley argumenta "contra la manera de pensar que extiende deliberadamente los métodos impersonales, reductivos y atomistas, apropiados para las ciencias físicas, a las investigaciones sociales y psicológicas, donde funcionan mal [...] Esta extensión deliberada da la impresión de que algo llamado ciencia nos está prohibiendo ser humanos. Pero la ciencia no hace tal cosa. Las ciencias a las que actualmente se invoca para este proyecto son principalmente la neurología y el estudio de la evolución ${ }^{10}$.

Me apresuro a decir que, salvo interpretación forzada, ninguno de estos dos campos de investigación ofrece tal auxilio a las tesis del naturalismo radical. Y, sin embargo, el naturalismo es con mucho la posición dominante en la academia, hasta el punto de que muy pocos intelectuales osan discrepar. Y los pocos que lo hacen, enfrentándose a menudo a críticas ad hominem y a juicios de intención, saben que ponen en riesgo su fama y carrera. Pero quizá no hagan falta muchas voces para romper el actual consenso. Recordemos el famoso cuento del traje nuevo del emperador. Bastó una sola voz ingenua para que todos reconociesen lo que tenían delante de las narices, que el emperador iba desnudo.

Roger Penrose, en 1989, aplicaba el cuento al estado de la filosofía de la mente. En ese tiempo, la moda académica consistía en pensar la mente humana como un computador. Penrose escribió entonces su famoso libro La nueva mente del emperador ${ }^{11}$, en el que daba la voz de alerta: no, la mente humana no es algorítmica, no es un computador. A esta moda computacional ha venido a sumarse la moda naturalista, que quiere hacer de nosotros simples primates. Insisto en que son modas académicas. Fuera de la academia, cualquier persona sensata, y cualquier académico en horas libres, sabe la enorme y evidente diferencia que hay entre un ser humano y un robot, entre un ser humano y cualquier otro animal. Es decir, el naturalismo es actualmente hegemónico en medios intelectuales, pero la situación no es desesperada, antes bien, creo que es muy esperanzadora, pues ya están apareciendo algunas voces discrepantes. Y sabemos que con unas pocas voces basta cuando se trata de proclamar lo evidente. Lo evidente, en este caso, es que el edificio del naturalismo radical, asentado sobre las ruinas del viejo materialismo, también amenaza ruina.

El enfoque naturalista radical lleva en sí el germen de su propia destrucción ${ }^{12}$. Solo desde la mirada unificadora de la conciencia, surge la naturaleza como un todo, como un cosmos. Si el ser humano fuese solo naturaleza, ni siquiera naturaleza habría, sino tan solo fragmentos. Dicho de otro modo, si el ser humano fuese solo naturaleza, entonces sus facultades serían estrictamente recursos para la supervivencia, una modulación estilizada de los dientes y garras que otros animales exhiben. Si fuese así, no podríamos confiar en que nos acercasen un palmo a la verdad, al bien o a la belleza. ¿Qué sentido tendría entonces afirmar la verdad del naturalismo radical?

\section{2. ¿EL NATURALISMO RADICAL EN CRISIS?}

A pesar de su posición todavía dominante, ya hay unas pocas voces denunciando las más que evidentes grietas del edificio naturalista. Recordemos: para señalar lo evidente

10 Midgley, M. (2002): Science and Poetry. Londres: Routledge, pp. 1-2.

11 Penrose, R. (1991): La nueva mente del emperador. Madrid: Mondadori (R. Penrose (1989): The Emperor's New Mind. Oxford: OUP; traducción de J. García Sanz).

12 Cf. Plantinga, A. (2008): "Against Naturalism», en Plantinga, A. y Tooley, M. (2008): Knowledge of God. Oxford: Blackwell; CAStro, S. (2012): Lógica de la creencia. Salamanca: San Esteban. 
solo hace falta una mano, para ocultarlo, muchas. Según Nicholas Rescher, «exagerar las aspiraciones de la ciencia hasta el punto de sostener que tiene "todas las respuestas" sobre la condición del hombre, el sentido de la vida o los asuntos de política social, es dar un paso peligroso [...] Esta visión hinchada de las capacidades invita al escepticismo y a la hostilidad como secuela de la frustración de las expectativas, que es su consecuencia inevitable ${ }^{13}$, pues «el hombre — continúa Rescher- es miembro no solo del orden natural de las cosas, sino del específicamente humano ${ }^{14}$. La afirmación de Rescher es sencilla y bastante evidente: el ser humano es miembro del orden natural, sí, pero también del específicamente humano; no es, pues, reductible a pura naturaleza.

En la misma línea de reconocimiento de los límites del naturalismo, podemos citar un reciente y polémico libro de Thomas Nagel. El subtítulo del mismo ya es significativo: "Por qué la concepción materialista neo-darwinista de la naturaleza es casi con seguridad falsa». Según Nagel, «la actual ortodoxia sobre el orden cósmico es el producto de supuestos rectores carentes de apoyo y que van en contra del sentido común» ${ }^{15}$. La «actual ortodoxia» viene descrita en estos términos: "la forma vigente del naturalismo es un materialismo reduccionista que intenta captar la vida y la mente gracias a su extensión neo-darwinista, es el triunfo heroico de una teoría ideológica sobre el sentido común $»^{16}$. Hoy día, la oposición a dicha ortodoxia se considera «no solo científicamente, sino también políticamente incorrecta» ${ }^{17}$.

La razón por la cual esta doctrina "oficial» sobre el cosmos es errónea tiene que ver principalmente con la presencia en el mismo de la autoconciencia humana: «La conciencia es el obstáculo más conspicuo para un naturalismo completo [...] La existencia de la conciencia parece implicar que la descripción física del universo, a pesar de su riqueza y poder explicativo, es solo parte de la verdad ${ }^{18}$. «Los sujetos conscientes y su vida mental son componentes inevitables de la realidad, no descriptibles por las ciencias físicas» ${ }^{19}$. "Si el reduccionismo psico-físico es excluido — concluye Nagel一, entonces toda nuestras comprensión naturalista del universo queda infectada, no solo nuestra comprensión de la conciencia» ${ }^{20}$.

Se podría alegar que existen diversas teorías reduccionistas de la mente, como pueden ser el conductismo, el funcionalismo, el eliminativismo, las teorías de la identidad o la llamada inteligencia artificial fuerte. La mejor respuesta que conozco ante esta objeción es la que ha aportado el filósofo norteamericano John Searle en su libro The Rediscovery of the Mind: hay algo que todas estas teorías olvidan y dejan sin explicar: la mente ${ }^{21}$.

A estas voces de Midgley, Rescher, Searle o Nagel, contrarias a una intelección materialista de la naturaleza, y en especial de la naturaleza humana, se añade la de Raymond Tallis ${ }^{22}$. Para empezar, el libro de Tallis es valioso por la concisa y acertada

13 Rescher, N. (1994): Los límites de la ciencia. Madrid: Tecnos, p. 243. (Rescher, N. (1984): The Limits of Science. Berkeley: University of California Press).

14 Rescher, N., op. cit. 245 (cursiva en el original).

15 Nagel, Th. (2012): Mind and Cosmos. Oxford: OUP, p. 5.

16 NAGEL, TH., op. cit. 128.

17 Nagel, TH., op. cit. 5.

18 NAgel, TH., op. cit. 35.

19 Nagel, TH., op. cit. 41.

20 NAGEL, TH., op. cit. 43.

21 Cf. SEArLe, J. (1992): The rediscovery of the Mind. Cambridge: The MIT Press, p. 30.

22 Tallis, R. (2011): Aping Mankind. Neuromania, Darwinitis and the Misrepresentation of Humanity. Durham, UK: Acumen. 
caracterización que hace de la actual ortodoxia naturalista. Dicho en breve, la caracterización sería como sigue.

Los seres humanos somos mera materia sometida a fuerzas naturales. Ahora bien, es obvio que resultamos un poco más complicados y enigmáticos que una piedra. En este punto, el darwinismo es llamado en auxilio del materialismo: en nuestro caso, la materia ha adquirido cierta complejidad gracias al ciego proceso de evolución por selección natural, hasta formar un organismo de una cierta especie. Cada uno de nosotros es, pues, un organismo de la especie Homo sapiens, un primate. Y toda la información necesaria para la constitución de los organismos se halla en sus genes. Bien, pero seguimos siendo más complicados y enigmáticos que, por ejemplo, una ameba. Llegados aquí, el naturalismo se aferra a las neurociencias como a clavo ardiente. El cuento sigue así: a partir de los genes se construye todo el organismo humano, incluido el cerebro, cuyas conexiones neuronales darán cuenta de toda nuestra vida mental. Eso es todo y a eso hay que reducir todas las características humanas que aparentemente van más allá del ámbito natural.

En consecuencia, los naturalistas radicales se otorgan a sí mismos la tarea de naturalizar (o simplemente negar) la libertad, la voluntad, la conciencia y la autoconciencia, los valores epistémicos, morales y estéticos, el lenguaje y la intencionalidad, la sociabilidad, la religiosidad, el altruismo y un largo etcétera de rasgos que desde el sentido común consideraríamos como irreductiblemente humanos. En esta maniobra, algunos naturalistas han dislocado e inflamado el darwinismo, que en principio era una respetable teoría biológica, hasta convertirlo en una especie de horizonte metafísico último. Y, a partir de las neurociencias, han desarrollado una auténtica neuromanía ${ }^{23}$.

Permítaseme, antes de seguir, que haga una aclaración imprescindible. Hay que diferenciar nítidamente entre materia y materialismo, naturaleza y naturalismo, ciencia y cientificismo, darwinismo y darwinitis, neurociencia y neuromanía. Con ello quiero decir que podemos admirar la naturaleza y la ciencia, respetar las teorías darwinistas e investigar con interés en neurociencia; y todo eso es compatible con la crítica al naturalismo radical y al cientificismo, con el diagnóstico de la darwinitis y de la neuromanía. Y esto es precisamente lo que hace Tallis. Según él, la darwinitis y la neuromanía resultan «malas para la humanidad» ${ }^{24}$ : «Si cualesquiera ideas son importantes, entonces las ideas sobre el tipo de criaturas que somos han de ser de suprema importancia» ${ }^{25}$.

Tallis muestra con argumentos, en mi opinión, convincentes, que no hay razones científicas que justifiquen la concepción naturalista del ser humano. El naturalismo no viene exigido por la biología evolucionista ni por las neurociencias. Solo desde una interpretación abusiva de las mismas se puede predicar tal cosa. Es muy importante que investiguemos sobre nuestros genes y neuronas, pero no todo lo humano es reducible a genes y neuronas. El Proyecto Genoma Humano nos ha aportado información valiosísima, pero no ha descifrado la naturaleza humana. Otro tanto sucederá con los actuales proyectos de investigación sobre el cerebro y las conexiones neuronales. Quien espere de ellos la clave de lo humano se verá decepcionado, del mismo modo que se vieron decepcionados quienes la esperaban del PGH. El ser humano no cae enteramente

23 Una denuncia de esta situación la encontramos en SATEL, S. y LiLIEnfeld, S. O. (2013): Brainwashed: The Seductive Appeal of Mindless Neuroscience. NewYork: Basic Books. Véase también BurToN, R. A. (2013) A Skeptic's Guide to the Mind: What Neuroscience Can and Cannot Tell Us About Ourselves. New York: St. Martin's Press.

24 TAllis, R., op. cit. 9.

25 TAlLis, R., op. cit. 10. 
dentro de la naturaleza ${ }^{26}$, tenemos características que «nos separan del resto del mundo natural ${ }^{27}$. Tallis cita y analiza algunas de ellas, pero el argumento clave para él es que tenemos la capacidad de ser explícitos. Es decir, los otros animales tienen comportamientos que pueden ser razonables, pero solo un humano puede hacer explícitas ante sí mismo las razones de sus decisiones, puede entonces evaluarlas, revisarlas y modular en consecuencia sus comportamientos. Puede, además, presentar estas razones ante los demás, y juntos examinarlas en colaboración.

\section{Naturalismo y teología}

Alguien podría objetar que la crítica al naturalismo va de la mano de la creencia en alguna entidad sobrenatural. Pero, de hecho, tanto Nagel, como Searle y Tallis se declaran ateos. Para ellos, la crítica al naturalismo radical no es cuestión de teología, sino de sentido común. Por cierto, no hay por qué suponer otra cosa respecto de los científicos y filósofos teístas. La mera sospecha de que sus argumentos pudieran estar sesgados por sus creencias sería, en opinión de Nagel, «manifiestamente injusta ${ }^{28}$. En principio, hay que suponer la misma honradez intelectual a todos.

En palabras de Tallis: «En la defensa de las humanidades, el arte, el derecho, la ética, la economía, la política e incluso las creencias religiosas frente al reduccionismo neuro-evolucionista, los humanistas ateos y los teístas tienen una causa común, y en el naturalismo reduccionista y cientificista un común adversario ${ }^{29}$.

Y, en efecto, también desde posiciones teístas le llegan las críticas al naturalismo radical. «Es cuestión de vida o muerte — afirma Francisco Soler- el mostrar la distinción entre los resultados científicos y la lectura materialista de los mismos. Porque realmente son distintos ${ }^{30}$. Cuando los naturalistas insisten en atribuirse alguna ventaja procedente de la propia ciencia, y habida cuenta de que tal ventaja no existe, lo que logran es transformar el naturalismo en mera ideología o, como afirma Soler, en una errónea mitología. La desconexión entre ciencias naturales y naturalismo es urgente y beneficiosa para todos: «[es] mejor incluso para las interpretaciones materialistas de las teorías científicas, ya que entonces dejarán de moverse en el ámbito de la mitología, y volverán al terreno de las propuestas filosóficas, que es su verdadero sitio» ${ }^{31}$.

Soler, al igual que Tallis y Midgley, hace especial referencia al darwinismo y a las neurociencias. Según él, nada en la actual neurociencia exige una interpretación naturalista o materialista de la vida humana. Hay realidades en la misma que van mucho más allá del juego de conexiones neuronales. En esta misma línea, podemos citar también la opinión de Adela Cortina. En su libro Neuroética y neuropolítica, argumenta largamente en el sentido de que "no hay ética universal fundamentada en el cerebro» ${ }^{32}$. Es decir, las neurociencias hacen importantes aportaciones al conocimiento del ser humano, pero existen aspectos de la vida humana, tales como la moral, que no encuentran

26 «Humans are not part of nature: or not entirely», TALLIS, R., op. cit. 212.

27 TALlis, R., op. cit. 213.

28 «Manifestly unfair», NAGEL, op. cit. 10.

29 TALlis, R, op. cit. 336.

30 SOLER, F., op. cit. 317.

31 Soler, F., op. cit. 397.

32 Cortina, A. (2011): Neuroética y neuropolítica. Sugerencias para la educación moral. Madrid: Tecnos, capítulo 3 . 
explicación exclusiva ni fundamento último en el funcionamiento de nuestro cerebro. Algo análogo afirma Soler respecto de las teorías biológicas darwinistas, que no exigen, en absoluto, una interpretación naturalista, ni tienen por qué desembocar necesariamente en nihilismo moral, sino que son perfectamente compatibles con interpretaciones no materialistas, e incluso teístas, tanto del cosmos como de la naturaleza humana.

La línea sugerida por Nagel en su libro ya citado es, en mi opinión, de lo más inteligente que se ha escrito a este respecto, y creo que, desde su posición atea, ofrece claves de enorme valor también para los autores teístas. El pensamiento de Nagel tiene además una especial repercusión pública, de modo que puede servir de punto de apoyo para cambiar el vigente status quo. Una prueba de la influencia cultural que puede proyectar su pensamiento está en la atención que le dedican los grandes medios de comunicación globales. En este sentido, me parece muy valioso el resumen de su libro que el propio autor ha publicado en The New York Times (18 de agosto de 2013). Destaco y comento un fragmento: "A pesar de que la visión teísta, en algunas versiones, es consistente con la evidencia científica disponible, yo no creo en ella; me atrae, en cambio, una alternativa naturalista aunque no-materialista [...] Tiene sentido buscar una forma ampliada de entendimiento que incluya lo mental pero que siga siendo científica, es decir, que siga siendo una teoría del orden inmanente de la naturaleza [...] Querría añadir que incluso algunos teístas podrían encontrarlo aceptable, ya que pueden mantener que Dios es el responsable último de tal orden natural ampliado, como creen que lo es de las leyes físicas» ${ }^{33}$.

Según Nagel, se requiere una nueva perspectiva científica, que supere las estrecheces metodológicas de la ciencia moderna, y que incluya, posiblemente, explicaciones en clave teleológica. Sin tal ampliación, la ciencia contemporánea, apegada a la ortodoxia vigente, no logrará dar cuenta de una parte muy importante del cosmos, a saber, la mente. La ciencia ampliada en el sentido que propone Nagel sería compatible tanto con una visión teísta como con una visión no teísta de la realidad. Es más, el actual estado de la ciencia, como queda claro en la cita anterior, es compatible con ambas. Dicho de otro modo, el progreso científico no tenía por objetivo al comienzo de la modernidad la exclusión de Dios, y al final de la misma sabemos que tampoco ha producido tal exclusión como resultado, por más que muchos hayan querido buscarla. Incluso pensadores ateos, como Nagel o Tallis lo reconocen ya abiertamente.

Por otro lado, en la propuesta de una visión naturalista pero no materialista de la realidad podemos encontrarnos muchos, tanto teístas como no teístas. Por eso Nagel dice que su naturalismo - llamémosle - moderado puede ser aceptado también por los teístas. Coincido con Nagel. Mientras que el naturalismo radical resulta obviamente excluyente, el naturalismo moderado, no materialista, humanista y abierto a una posible trascendencia, es un terreno común sobre el que fundar una idea sensata de naturaleza humana. Se trata, en última instancia, de la idea de naturaleza humana propia del sentido común.

De modo complementario, reconozcamos que el avance de la ciencia en los últimos siglos tampoco ha cerrado el debate sobre la realidad de Dios a favor de posiciones

33 "Even though the theistic outlook, in some versions, is consistent with the available scientific evidence, I don't believe it, and am drawn instead to a naturalistic, though non-materialist, alternative [...] It makes sense to seek an expanded form of understanding that includes the mental but that is still scientific - i.e. still a theory of the immanent order of nature [...]. I would add that even some theists might find this acceptable; since they could maintain that God is ultimately responsible for such an expanded natural order, as they believe he is for the laws of physics» (NAGEL, TH., "The Core of "Mind and Cosmos", en The New York Times, 13/08/2013). 
teístas. El debate permanece abierto. Pero ahora estamos allanando un terreno común, en el que cabemos todos, teístas y no teístas, y sobre el cual se puede edificar una idea común y sensata de naturaleza humana.

Hasta aquí las conclusiones que podemos extraer para la cuestión de la naturaleza humana. Pero me gustaría añadir una posible línea de desarrollo de estas ideas de Nagel en el plano teológico. Tres o cuatro siglos de avances científicos no han producido un dictamen sobre Dios. Es un hecho. ¿Este hecho merece una explicación? Creo que sería interesante buscarla. ¿Se podría ofrecer tal explicación desde una perspectiva no teísta? Francamente, no lo sé. Y, ¿desde una perspectiva teísta? Quizá sí. Razonando abductivamente, al estilo de Peirce, podríamos decir que la hipótesis de un Dios creador bondadoso explica bien el hecho referido. Al fin y al cabo, era lo esperable para un teísta. La realidad de Dios, con sus implicaciones prácticas, ha de estar, según esta hipótesis, al alcance de todos los humanos, y no solo de una élite. Esta apreciación ha tenido un profundo desarrollo filosófico en el texto de Peirce titulado «Un argumento olvidado en favor de la realidad de Dios ${ }^{34}$. Pero, al mismo tiempo, no se ha de imponer a nadie la realidad de Dios de modo irresistible. Si el ser humano estuviera hecho a imagen y semejanza de un Dios libre, habría de ser él mismo hasta cierto punto libre; libre, entre otras cosas, para creer en la realidad de Dios. Es más, la hipótesis de Dios permite hacer una predicción: la ciencia futura seguirá siendo compatible tanto con una visión teísta como con una visión no teísta de la realidad. Todo ello no quiere decir que la ciencia natural y la teología sean mutuamente irrelevantes, ni mucho menos, tan solo indica que sus muchas aportaciones mutuas no servirán para zanjar definitivamente determinadas cuestiones. La abducción, en este caso, aporta además una cierta elegancia lógica: hay que reparar en que el éxito explicativo o incluso predictivo de una hipótesis la hace razonable, plausible, pero nunca completamente cierta, lo cual es perfectamente coherente con la propia hipótesis que hemos considerado, la de un Dios que se hace accesible a todos pero que no se impone a nadie.

\section{Naturaleza humana y SENTido COMÚN}

Desde la experiencia cotidiana y el sentido común podemos obtener, pues, valiosas indicaciones sobre la naturaleza humana ${ }^{35}$. Todos somos conscientes de nuestra naturaleza física y biológica, cargamos con nuestro peso, notamos la sed y el hambre. Del mismo modo nos percatamos de nuestros numerosos vínculos sociales, de los cuales dependemos a lo largo de toda la vida. A un tiempo, estamos abiertos a una esfera espiritual, pues tenemos una innegable conciencia de lo que nos rodea y de nosotros mismos, sabemos que podemos deliberar racionalmente y actuar libremente, que decidimos a diario nuestras acciones y a largo plazo el itinerario de nuestras vidas. Nos consta, en contrapartida, que todo ello está sometido a ciertos límites, condiciones e indicaciones, que nuestra libertad no es absoluta.

34 PeIrce, C. S. (1996): Un argumento olvidado en favor de la realidad de Dios, (Introducción, traducción y notas de Barrena, S. F.), Cuadernos de Anuario Filosófico. Pamplona: Servicio de Publicaciones de la Universidad de Navarra.

35 Esta idea tiene aplicaciones prácticas inmediatas, por ejemplo, en el terreno de la bioética. Puede verse, en este sentido: MARcos, A. (2013): «El sentido común en la bioética». Cuadernos de Bioética. $\mathrm{XXIV/2,} \mathrm{pp.} \mathrm{155-167.}$ 
Por añadidura, no hace falta ir mucho más allá del sentido común para darse cuenta de que, en condiciones normales, estos tres aspectos de mi realidad humana no funcionan por separado, no constituyen sustancias mutuamente ajenas, no están enlazados por mero accidente. Son aspectos que pertenecen a una sola entidad, que conforman una sola y única sustancia, la persona que yo soy.

El sentido común y la experiencia cotidiana nos invitan a pensar en una imagen del ser humano en la que se reconozca la unidad de la persona, así como sus aspectos biofísicos, sociales y espirituales. Una elaboración filosófica de esta experiencia humana común podemos encontrarla en la tradición aristotélica, para la cual el hombre es un animal, social y racional (zoon politikon logon), y todo ello unido e integrado. Aristóteles, en su tratado Sobre las Partes de los Animales (643a 24), escribió que «la forma es la diferencia en la materia» (to eidos en te hyle). Esta profunda intuición metafísica es la que permite aunar todos nuestros rasgos (diferencias), biológicos, sociales y espirituales, en una sola y única sustancia, sin que ninguno de ellos quede anulado por los otros, sino todos integrados ${ }^{36}$.

Alfredo Marcos

[Artículo aprobado para publicación en diciembre de 2014].

36 Cf. Marcos, A. Postmodern Aristotle, Cambridge Scholars Publishing, Newcastle, UK, 2012. Véase la entrada «Difference», en la p. 153. 